\title{
Los imaginarios sociales como campo de interpretación para el Trabajo Social: el caso de la desigualdad ${ }^{\star}$
}

\author{
Marcela Flotts ${ }^{\star \star}$
}

\begin{abstract}
La creciente complejidad de lo social desafía constantemente cualquier intento de transformación social. La persistencia de problemas sociales como la pobreza y la desigualdad, no pueden sino ser el foco de atención de profesiones como el Trabajo Social, cuya vocación más profunda es el cambio social. La encarnación de esta vocación, vale decir, la intervención social, debe apoyarse en herramientas que permitan al profesional fundamentar su acción, desde una profunda comprensión de los fenómenos sociales a fin de hacer emerger nuevas dimensiones de dichos fenómenos. Los imaginarios sociales, entendidos como aquellas representaciones colectivas que nos permiten relacionarnos con el entorno, constituyen una interesante apuesta para una comprensión compleja en Trabajo Social. El presente artículo muestra parte de los resultados de una investigación acerca de los imaginarios sociales relativos a la desigualdad en Chile y su pertinencia y utilidad para satisfacer el constante deseo de transformación del Trabajo Social.
\end{abstract}

Palabras clave: Imaginarios sociales, desigualdad, Trabajo Social, comprensión social

\section{Os imaginários sociais como campo de interpretação para o Trabalho Social: o caso da desigualdade}

\section{RESUMO}

A crescente complexidade da dimensão social desafia constantemente qualquer tentativa de transformação social. A persistência de problemas sociais como a pobreza e a desigualdade não pode deixar de ser o centro das atenções de profissionais como o Trabalho Social, vocacionados profundamente à mudança social. A personificação desta vocação, isto é, a intervenção social, deve se apoiar em instrumentos que permitam que o profissional fundamente sua ação, desde uma profunda compreensão dos fenômenos sociais, para poder fazer emergir novas dimensões dos referidos

Artículo recibido el 31 de julio. Artículo aprobado el 10 de septiembre.

** Chilena. Trabajadora social. Académica e investigadora Universidad Andrés Bello.E-mail: mflotts@unab.cl 
Los imaginarios sociales como campo de interpretación para el Trabajo Social: el caso de la desigualdad / Flotts

fenômenos. Os imaginários sociais, entendidas como aquelas representações coletivas que permitem relacionar-nos com o ambiente, constituem uma interessante aposta para uma complexa compreensão em Trabalho Social. O presente artigo apresenta parte dos resultados duma investigação sobre os imaginários sociais relativos à desigualdade no Chile e sua pertinência e utilidade para satisfazer o desejo constante de transformaç4ao do Trabalho Social.

Palavras-chave: Imaginários sociais, desigualdade, trabalho social, compreensão social.

\title{
Social Imaginaries as an interpretative field for social work: the case of inequality
}

\author{
ABSTRACT
}

The growing complexity of the social dimension constantly challenges any attempt of social transformation. The persistence of social problems such as poverty and inequality can only be the focus of professions such as Social Work, whose deepest vocation is social change. The incarnation of this vocation, that is to say, social intervention, must be based on tools that allow the professional to base his action from a deep understanding of social phenomena in order to bring forth new dimensions of these phenomena. Social imaginaries, understood as those collective representations that allow us to relate with the environment, constitute an interesting bet for a complex understanding in Social Work. The present article shows part of the results of an investigation about the social imaginaries related to inequality in Chile and its pertinence and usefulness to satisfy the constant desire to transform Social Work.

Key words: Social Imaginaries, inequality, Social Work, social understanding.

\section{Presentación}

Las propuestas contemporáneas del Trabajo Social respecto a su horizonte de intervención, dejan de manifiesto que la acción profesional sin reflexión y sin comprensión acerca de lo social, aplaca todo intento de transformación social. Surge entonces la imperiosa necesidad por contar con mecanismos de comprensión que permitan capturar, en la medida de lo posible, la complejidad que envuelve hoy a los fenómenos sociales.

La apuesta de este artículo es reflexionar en torno a cómo los imaginarios sociales pueden constituir un valioso dispositivo de com- 
prensión social compleja, toda vez que mediante ellos se logra entrar en el espacio de la intangibilidad de lo social, donde probablemente está depositada gran parte de esa complejidad de la que tanto ha dado cuenta la disciplina del Trabajo Social.

Específicamente, el artículo se basa en los resultados -aún parciales- de una investigación ${ }^{2}$ que busca conocer la configuración de los imaginarios sociales sobre la desigualdad en Chile. Con ello se busca cumplir con dos objetivos: (i) en lo concreto, aportar (mediante parte de los resultados de la investigación) a la discusión sobre la desigualdad en Chile, y (ii) en lo disciplinar, compartir (mediante los aprendizajes de la experiencia investigativa) los aportes del estudio de los imaginarios sociales como ámbito de producción de conocimiento para el Trabajo Social y su afán de comprensión y transformación social.

En una primera instancia se expondrán los principales antecedentes de la investigación, dando cuenta del problema abordado y la apuesta metodológica. En segundo lugar, se ofrecerá un breve recorrido conceptual sobre los imaginarios sociales. En un tercer momento, el artículo mostrará parte de los resultados de la investigación y los análisis que ellos sugieren y, por último, el cuarto apartado expone las reflexiones finales que principalmente se abocan a proponer a los imaginarios sociales como mecanismos aptos de comprensión para el Trabajo Social.

\section{Antecedentes}

Chile se ha caracterizado históricamente por sus altos niveles de desigualdad económica y su elevada concentración de la riqueza. Los ingresos del 10\% más rico son 26 veces más altos que los del $10 \%$ más pobre y es el país con mayor desigualdad de ingresos dentro de los países de la OECD (OECD, 2015). El índice de Gini, que es comúnmente utilizado para medir la distribución del

Se trata de la investigación doctoral de la autora, actualmente en curso, realizada en el marco del Doctorado en Ciencias Sociales de la Universidad de Chile. 
ingreso en los países, señala que además de su gran magnitud, el problema de la desigualdad en Chile es persistente y está lejos de mejorar. La siguiente tabla muestra los resultados de esta medición para el país en los últimos años:

Tabla Nº1. Índice de Gini, Chile, periodo 1990-2013

\begin{tabular}{|c|c|}
\hline Año & Índice de Gini \\
\hline 1990 & 0.57 \\
\hline 1996 & 0.55 \\
\hline 2000 & 0.55 \\
\hline 2003 & 0.54 \\
\hline 2006 & 0.51 \\
\hline 2009 & 0.52 \\
\hline 2011 & 0.50 \\
\hline 2013 & 0.50 \\
\hline
\end{tabular}

Fuente: elaboración propia en base a datos del Banco Mundial (2016)

Si bien ha existido un leve descenso, los datos demuestran que la distribución del ingreso en Chile se mantiene altamente inequitativa. Para contextualizar respecto a lo que sucede en otras regiones del mundo, se puede señalar que en los países de la OCDE (excluyendo a México y Chile) el promedio del índice de Gini es de 0.31 (Banco Mundial, 2012); en Latinoamérica (18 países) alcanza un 0.52 (CEPAL, 2012). En Estados Unidos la cifra llega a un 0.37; en Noruega a un 0.25; en Holanda a un 0.30; y en Canadá a un 0.32 (Banco Mundial, 2012).

Ahora bien, contraintuitivamente, este contexto altamente desigual, se contrapone a diversos estudios que muestran percepciones tendientes a legitimar tal desigualdad (Flotts, 2016). Un discurso que demanda una sociedad más justa convive con niveles altos de tolerancia hacia las desigualdades (Castillo, 2009, 2012a, 2012b; Garretón y Cumsille, 2000; Puga, 2011).

Siendo un problema mundial y especialmente agudo en América Latina y Chile, la desigualdad ha sido un tema ampliamente estu- 
diado en las Ciencias Sociales. Desde la sociología, por ejemplo, las investigaciones se han concentrado en estudiar las desigualdades sociales como tales, las acciones colectivas para enfrentarlas o las políticas públicas diseñadas para reducirlas (Mac-Clure y Barozet, 2015). Así, mientras la desigualdad se ha considerado como un complejo fenómeno social que ha recibido amplia atención en los estudios sociales, la igualdad ha sido un ámbito menos abordado y su interacción con las concepciones de desigualdad no ha sido explicitada teórica ni empíricamente.

De acuerdo a Araujo (2013), a pesar de lo evidente que puede parecer la relevancia de estudiar las percepciones sobre las desigualdades puestas en referencia a los principios normativos de igualdad presentes en una sociedad, el debate en ciencias sociales no ha abordado dicha interrelación, existiendo una masa importante de estudios sobre la desigualdad, pero no así sobre la igualdad. La justicia social ha sido menos abordada como contraparte para medir desigualdad (Mac-Clure y Barozet, 2015) y en ese sentido, la igualdad se ha mantenido como una construcción normativa abstracta atendida principalmente desde la filosofía. Sin embargo, el principio de igualdad es un problema sociológico, al igual que la desigualdad (Araujo, 2013).

De esta forma, la investigación se ha propuesto cubrir en parte tal déficit, estudiando los imaginarios sociales sobre la igualdad y la desigualdad en Chile, como una propuesta para avanzar hacia la comprensión de aquello que consideramos justo y que implica percibir a un contexto altamente desigual de una determinada manera.

La investigación se llevó a cabo mediante una metodología mixta. Por un lado, mediante la fase cuantitativa se logró describir las configuraciones colectivas de los imaginarios sociales sobre la igualdad y la desigualdad, a través del análisis de los datos proporcionados por la Encuesta LAPOP $2012^{3}$. Por su parte, la fase cua-

3 La encuesta LAPOP (Latin American Public Opinion Project) es un proyecto de la Vanderbilt University, Estados Unidos, que busca producir información de alta calidad en América Latina, en variados temas sociales, de política y economía. Para 
litativa implicó entrevistar a representantes de diversos sectores sociales del país (político, económico, sindical, tercer sector, religioso, académico, medios de comunicación) para estudiar cómo los discursos y percepciones de estas personas incorporan o manifiestan la configuración de los imaginarios.

Con todo ello se logró cumplir con los objetivos de la investigación y levantar variados resultados, parte de los cuales se presentan en el artículo.

\section{Breve recorrido conceptual sobre imaginarios sociales}

Desde el psicoanálisis, el griego Cornelius Castoriadis ha sido uno de los autores más relevantes que ha utilizado el término para referirse a las significaciones sociales imaginarias que le otorgan una unidad a la sociedad, derivadas de un entretejido de sentidos o significaciones que penetran en lo social para dirigirlo y orientarlo (Castoriadis, 2006). Son imaginarios porque no son ideas racionales ni objetos naturales, son creaciones de la imaginación, no individuales, sino que sociales: por eso lo llama imaginario social, que "no son nada si no son compartidos, participados, por ese colectivo anónimo, impersonal, que es también cada vez la sociedad" (Castoriadis, 2006: 79).

Ahora bien, este trabajo se basa en las corrientes sociológicas y filosóficas sobre imaginarios sociales, especialmente desde los aportes de cuatro autores: el filósofo e historiador polaco francés Bronislaw Baczko, quien introduce al concepto de los imaginarios sociales los sistemas de valores a los cuales las personas adhieren; el filósofo canadiense Charles Taylor, quien enfatiza el rol de los imaginarios sociales respecto a las expectativas y relaciones entre los individuos; el sociólogo chileno Manuel Antonio Baeza, quien considera la re-

ello, cada cierto año aplica una encuesta de opinión. En 2012, la encuesta aplicada en Chile consideró una muestra de 1.571 personas, hombres y mujeres mayores de 18 años de todo el territorio nacional. Para mayor información, visitar http://www. vanderbilt.edu/lapop/ 
levancia de las matrices de sentido que regulan el modo en que la sociedad se piensa desde determinados imaginarios sociales, y el sociólogo español Juan Luis Pintos, cuya propuesta de imaginarios sociales se centra en las construcciones colectivas de la realidad social en un tiempo y un espacio determinado.

Baczko conceptualiza a los imaginarios sociales como "referencias específicas en el vasto sistema simbólico que produce toda colectividad y a través de la cual ella se percibe, se divide y elabora sus finalidades" (Baczko, 1991: 28), produciendo una representación de sí misma y un orden totalizante en una sociedad. El imaginario social se constituye entonces como una fuerza reguladora de la vida colectiva. No sólo otorgando sentido de pertenencia a los individuos, sino también definiendo las formas de relación entre ellos y las instituciones y controlando la vida colectiva y el ejercicio del poder (Baczko, 1991). Se trata de un esquema de interpretación y de valoración, por lo que los imaginarios sociales promueven la adhesión a un sistema de valores e intervienen en la conducta de las personas, conduciéndolas a acciones comunes (Baczko, 1991).

Para Talyor, los imaginarios sociales constituyen el "modo en que (las personas) imaginan su existencia social, el tipo de relaciones que mantienen unas con otras, el tipo de cosas que ocurren entre ellas, las expectativas que se cumplen habitualmente y las imágenes e ideas normativas más profundas que subyacen a estas expectativas" (Taylor, 2006: 37). Para el autor, los imaginarios sociales son compartidos por amplios grupos de personas, mediante una concepción colectiva de la realidad que hace posible las prácticas sociales, otorgando un sentido común a aquello que se legitima cotidianamente (Taylor, 2006). Los imaginarios sociales siempre son complejos, debido a que incorporan las expectativas que tienen los individuos, unos de otros, respecto a las prácticas que se dan en la vida social, lo que es al mismo tiempo fáctico y normativo, es decir, otorgan "una idea de cómo funcionan las cosas normalmente, que resulta inseparable de la idea que tenemos de cómo deben funcionar y del tipo de desviaciones que invalidarían la práctica" (Taylor, 2006: 38). 
Por su parte, Baeza señala que los imaginarios sociales son construcciones mentales que dan significado práctico y sentido existencial a la vida social, mediando entre la realidad y la percepción acerca de ella (Baeza, 2000). De acuerdo al autor, implican una forma compartida en que los individuos representan el tiempo y el espacio, siendo formas creativas de vivenciar lo desconocido y actuando como matrices de sentido del discurso, el pensamiento y la acción. Rescata también su gran influencia en la manera de actuar y pensar en la sociedad, constituyéndose como valiosos antecedentes para el análisis social.

Para Pintos, finalmente, los imaginarios sociales permiten "la elaboración y distribución generalizada de instrumentos de percepción de la realidad social construida como realmente existente (...) Es decir, la primera definición de los imaginarios sociales tiene que ver con la instrumentación del acceso a lo que se considere realidad en unas coordenadas espaciotemporales específicas" (Pintos, 1995: 9). Por lo tanto, los imaginarios permiten percibir algo como real, para explicarlo y poder intervenir operativamente sobre él. Pintos se aleja de manera explícita de las posturas psicoanalíticas sobre los imaginarios sociales (como la de Castoriadis señalada anteriormente), porque considera que éstos se producen por la interacción de las instituciones que están reconocidas y legitimadas en la sociedad.

En términos de las funciones que los imaginarios sociales cumplen, se pueden resumir en dos principales. La primera, se refiere a que los imaginarios regulan la acción social, provocando la adhesión a determinados valores, moldeando conductas e interviniendo en los distintos niveles de la vida colectiva (Baczko, 1991; Cegarra, 2012). La segunda función, es que los imaginarios permiten elaborar los instrumentos con los cuales los individuos perciben la realidad socialmente construida como realmente existente. Así, su análisis facilita el acceso a la realidad en un tiempo y espacio específico, mediante categorías de comprensión de los fenómenos sociales (Pintos, 1995; Baeza, 2000). 


\section{Resultados}

A continuación se presenta parte de los resultados de la investigación. Considerando información producida tanto desde el análisis cuantitativo como el cualitativo, se describirán tres aspectos vinculados al contenido de los imaginarios sociales sobre la igualdad y la desigualdad en Chile: (i) el componente histórico de la desigualdad en el país, (ii) las tensiones entre la naturalización, la crítica y la legitimidad a la desigualdad y (iii) la sobrevaloración del mérito como promotor de justicia en un régimen neoliberal consolidado.

\section{a) El componente histórico de la desigualdad en Chile}

Los imaginarios sociales hablan de un reconocimiento al problema de la desigualdad en el país, acentuando su componente histórico como un problema que ha sido persistente en el tiempo dentro de nuestra sociedad. Como se puede ver en la tabla $\mathrm{N}^{\circ} 1$, el fenómeno es reconocido, si bien no en un alto porcentaje, como el tercer principal problema que enfrenta el país.

Tabla N². Cuál es el principal problema que presenta el país

\begin{tabular}{|l|c|}
\hline Problema & $\%$ \\
\hline Delincuencia, crimen & 30,8 \\
\hline Educación, falta de, mala calidad & 12,5 \\
\hline Desigualdad & 11,3 \\
\hline Desempleo/falta de empleo & 8,4 \\
\hline Pobreza & 4,3 \\
\hline Corrupción & 4 \\
\hline Economía, problemas con, crisis de & 3,6 \\
\hline Mal gobierno & 3,5 \\
\hline Salud, falta de servicio & 3,3 \\
\hline
\end{tabular}

Fuente: Elaboración propia en base a Encuesta LAPOP 2012

Resulta interesante resaltar que se encontró una relación estadísticamente significativa con la variable "nivel educacional": las personas con mayor nivel educacional, reconocen en mayor medida a 
la desigualdad como un problema en el país. Esto es coherente con lo que plantea Bucca (2016): las percepciones sobre la desigualdad dependen de la capacidad de las personas de acceder a procesos de información sobre la estratificación de la sociedad, cuestión que se logra con mayores niveles de educación.

El reconocimiento de la desigualdad como un problema grave dentro del país, se relaciona directamente con su configuración histórica y persistente dentro de la sociedad. Efectivamente, la desigualdad en Chile tiene sus raíces en patrones de desarrollo históricos que han favorecido la acumulación de riquezas y de capital, promoviendo las brechas económicas entre ricos y pobres (Flotts, 2016). Por ello, este problema no es producto ni de la globalización ni de las políticas recientes, sino que obedece a los modelos de desarrollo en América Latina durante los últimos doscientos años (Ottone y Vergara, 2007); tampoco es un fenómeno que obedezca a algún ciclo económico en particular.

Los discursos de los entrevistados también reconocen el componente histórico de la desigualdad:

Bueno, históricamente la gran dificultad que ha tenido Chile ha sido la desigualdad, no es algo nuevo (...) Para los países especialmente del Pacífico, la estructuración de la desigualdad se debe todavía a esta concepción más feudal, más monárquica del poder, el poder del dinero, de la información y del poder político y asociado en el pasado más al poder religioso, obviamente. Y eso ha costado mucho sacarlo de la cultura chilena, porque tiene muchas resistencias ideológicas (Entrevista representante tercer sector).

(...) hay una componente histórica de un país oligárquico, y que eso determina en gran parte lo que la actividad productiva de un país bien extractor de recursos naturales genera como riqueza, y que esa riqueza se concentra en pocas familias que son los herederos de los terratenientes de su momento y de la gente que llegó con capital para invertir y se mantuvo acumulando ese capital. Eso por un lado, o sea, la historia oligárquica por 
un lado (Entrevista representante sector político, tendencia izquierda).

Hay todo un tema de apropiación de capital, que tiene una dimensión histórica. Hay temas de renovación de capital, hay una estructura de impuestos, hay un tema sociopolítico histórico como fue la dictadura, hay toda una estructura ideológica que se sedimenta en los noventa también a nivel mundial que es que el Estado no debe intervenir, que los mercados se deben autorregular, y ese mercado autorregulador logró finalmente que aquellos que tenían una mejor posición frente al resto pudiesen tener, un poco lo que mostraba Pickety en ese sentido, ir aumentando sus ganancias en forma mayor que el resto, dentro también del florecimiento del capitalismo financiero, dentro de la desaparición de algunas posiciones como la baja del sector público, clase media tradicional (Entrevista representante sector académico).

La concentración histórica de los recursos productivos ha estado también acompañada desde épocas coloniales por una importante acumulación de influencia social, poder político y poder económico por parte de las elites; además, procesos de exclusión y discriminación de clases, de género y de etnias han marcado en forma importante los niveles de desigualdad (Ottone y Vergara, 2007).

El imaginario social en Chile, contiene la configuración histórica de la desigualdad.

\section{b) Naturalización, legitimidad y crítica a la desigualdad}

Como sostiene Bucca (2016), las creencias que las personas tienen sobre la desigualdad, son relevantes porque incorporan el grado de legitimidad que existe respecto a la estructura de estratificación social, a las percepciones sobre justicia social y a los posibles conflictos que genera la desigualdad, por lo que las demandas y apoyos que existan para promover mayor igualdad, se relacionan con la forma en que se percibe la desigualdad en un país. 
Inevitablemente relacionado con el componente histórico y con el reconocimiento de la desigualdad como un problema social, se puede señalar que la desigualdad está presente en la cotidianidad social. Zilveti (2016) plantea que la desigualdad emerge como un aspecto natural de la experiencia social y cotidiana.

Así, al estar histórica y culturalmente imbuida dentro de nuestros imaginarios, es posible asignarle una importante cuota de naturalización. Un 58,3\% de los chilenos tiende a creer que la desigualdad ha existido siempre y que no va a cambiar, tal como lo expresa la siguiente tabla:

Tabla N³. "Siempre han existido diferencias entre ricos y pobres y eso no va a cambiar"

\begin{tabular}{|l|c|}
\hline Grado de acuerdo & $\%$ \\
\hline 1 muy en desacuerdo & 12,1 \\
\hline 2 & 6,9 \\
\hline 3 & 9,6 \\
\hline 4 & 13,1 \\
\hline 5 & 17,8 \\
\hline 6 & 14,9 \\
\hline 7 muy de acuerdo & 25,6 \\
\hline
\end{tabular}

Fuente: Elaboración propia en base a Encuesta LAPOP 2012

La gran concentración de ingresos en Chile (recordemos las cifras del índice de Gini entregadas anteriormente), que agudiza la desigualdad económica, está tristemente ligada a otras formas de desigualdad que, al ser intangibles (y por lo tanto con menos posibilidades de ser medidas como en el caso de la desigualdad económica), sus sesgos de naturalización y legitimación son mayores. Nos referimos, por ejemplo, a la desigualdad de trato y las diferencias que surgen en el acceso a bienes y servicios, por la pertenencia a una determinada clase social.

Así lo refiere uno de los entrevistados:

Sí, yo creo que es el gran problema, quizás el problema más medular que hay en la política chilena. Y yo diría que es la 
desigualdad pero que tiene otra manifestación... vamos a buscarle el nombre, pero que no es sólo material, que se podría llamar clasismo, que se podría llamar falta de respeto o que se podría llamar ausencia de verdadera conciencia democrática. Pero que entra bastante en el terreno de la desigualdad. Te lo digo porque son muchos los otros lugares del mundo y no estoy pensando sólo en el mundo desarrollado, en Europa pasa bien claramente pero también incluso en otros países de América Latina, que habiendo diferencias en el dinero no las hay tan marcadas en la relación. Y que dos personas se puedan encontrar en un café, y que puedan conversar siendo uno millonario $y$ otro pordiosero, a mí me parece que es un objetivo muy central en una comunidad (Entrevista representante sector medios de comunicación).

Araujo (2013) señala al respecto que la distribución desigual de los recursos ha permeado en Chile el patrón de las interacciones sociales, caracterizado por relaciones jerárquicas y verticales que inciden en el trato entre las personas, en el ejercicio de la autoridad, en las condiciones para el reconocimiento y el grado de amabilidad.

Lo anterior está fuertemente incorporado en los imaginarios sociales de los chilenos. Así lo explica uno de los entrevistados:

Porque la gran mayoría de las personas en Chile reniegan sus orígenes. O sea, cuando tienen movilidad social, reniegan sus orígenes, entonces no se van a identificar con sectores de mayor pobreza y si se identifican dicen 'yo soy pobre de los buenos pero no de los malos'. Por eso la raíz es tan cultural, es tan fuerte. Porque además históricamente nos convencieron de esto, que asi tenía que funcionar la sociedad. Que yo tenía que tratar de pagarte lo menos posible, yo digo que es casi como la mentalidad de pirquinero, no es para ofender a los pirquineros, ellos hacen su pega, pero es la mentalidad de que yo exploto y la explotación es para mí. Y si alguien me ayuda, bueno, que agradezca que yo le pago, si es un favor el que yo le estoy haciendo. 
Eso es lo que está en la mentalidad, cuando uno discute con las personas dicen 'pero si el capital es mío, yo decido cuánto le pago, yo decido si a esa persona la contrato o no la contrato, por qué el Estado se tiene que meter en esto, me tiene que dejar libre. Si me deja libre, va a haber mucha más riqueza en Chile. Lo que por supuesto que la historia ha demostrado que no ha sido así. Al contrario, se acentúan las desigualdades y se acentúa la pobreza en sectores donde hoy en día hay mayor acceso a la información, inclusive al conocimiento y genera mayor frustración. O sea, la inestabilidad social es mucho más alta hoy día de lo que pudo haber sido en el pasado (Entrevista actor ámbito tercer sector).

Siguiendo con las propuestas de Araujo (2013), se puede señalar que los chilenos identifican como núcleo de la negación de la igualdad (o naturalización de la desigualdad), cuatro lógicas sistémicas que organizan las relaciones sociales. La primera es la lógica de las jerarquías naturalizadas, que promueve un patrón relacional fuertemente vertical. La segunda está referida a la lógica de los privilegios, fundamentada en experiencias que reemplazan la meritocracia por la nivelación a través de recursos como el "pituto", el apellido o las redes familiares. La tercera, la autora la llama la lógica de la confrontación de poderes, donde el abuso se impone en las relaciones por la desregulación del espacio social. Por último, está la lógica del autoritarismo y la desestimación de la autoridad, donde la relación con las normas aparece como una obligación acatada pasivamente más que como un consentimiento activo.

Veamos como expresa esta parte del imaginario social uno de los entrevistados:

Porque el pobre que está en un estado de postración tiene naturalizada también su miseria. Entonces lo que aquí corresponde y que creo que ya está aconteciendo, podemos decir cuán lento o cuán rápido, pero hay algo acá que está perdiendo su normalidad. Algo de eso tenían las marchas del 2011, en el fondo, que es un mundo que se quiere hacer oír, más allá de sus condi- 
ciones actuales. Y el trabajo acá consiste en que esos que están arriba y tienen naturalizada su situación es obvio que van a resistir por todos los medios mutarla. Para un blanco casarse con un negro, en el mundo sigue siendo difícil. Tienen que pasar muchas cosas antes de que eso pase. Para uno que ha nacido y vivido rico, sentirse igual a uno que ha nacido y vivido pobre, es muy difícil. A palos se sale de ahí (Entrevista actor sector medios de comunicación).

Ahora bien, ya nos referíamos anteriormente a las percepciones disímiles y contradictorias que pesan sobre la desigualdad en Chile. La marcada naturalización del fenómeno, que nos habla de un imaginario social que sitúa a la desigualdad en la vida cotidiana, coexiste con percepciones que tienden a criticarla.

Por ejemplo, los datos de la encuesta LAPOP indican que un $55,5 \%$ de los chilenos tiende a no estar de acuerdo con la frase "es bueno que exista desigualdad para que los pobres se esfuercen más", tal como lo muestra la siguiente tabla:

Tabla $\mathrm{N}^{\circ} 4$. Es bueno que exista desigualdad para que las personas más pobres se esfuercen más.

\begin{tabular}{|l|c|}
\hline Grado de acuerdo & $\%$ \\
\hline 1 muy en desacuerdo & 29,7 \\
\hline 2 & 12,6 \\
\hline 3 & 13,2 \\
\hline 4 & 15,4 \\
\hline 5 & 15,6 \\
\hline 6 & 8,5 \\
\hline 7 muy de acuerdo & 5,0 \\
\hline
\end{tabular}

Fuente: Elaboración propia en base a Encuesta LAPOP 2012

A pesar de lo anterior, un $29,1 \%$ tiende a estar de acuerdo, lo cual no deja de ser relevante.

Estas contradicciones inmersas en los imaginarios, se deben en parte a que las construcciones colectivas de la desigualdad se relacionan con la manera en que la justicia actúa como principio nor- 
mativo. Vale decir, la percepción social de las desigualdades debe ser entendida en relación a los principios normativos de igualdad presentes en una sociedad (Araujo, 2013). Las desigualdades sociales se reproducen tanto por razones estructurales como porque las personas las justifican o toleran en la vida cotidiana. Por ello, superar la desigualdad depende de que las personas las perciban como injustas (Mac Clure y Barozet, 2015). Ahí, por lo tanto, vemos cómo igualdad y desigualdad son dos caras de una misma moneda.

En ese sentido, el tipo de igualdad que desde hace décadas en Chile y América Latina se ha querido promover es la igualdad de oportunidades, que consiste en que todos puedan ocupar las mejores posiciones basándose en un principio meritocráctico, opción que es actualmente mayoritariamente aceptada (Dubet, 2011).

$\mathrm{Al}$ respecto, Puyol (2011) señala que existen diferencias respecto al tipo de desigualdad de resultados que la igualdad de oportunidades debe justificar. Para el autor, existe una primera forma de entender la igualdad de oportunidades, de índole "social", ligada a la percepción de injusticia que provoca el que se pueda predecir la posición social que ocupará una persona por el lugar donde nació o el apellido que tiene. La otra forma "considera que lo que es injusto es que algunas personas obtengan mayores beneficios que otras si, en realidad, se han esforzado menos (...) A esta versión la llamo concepción individualista de la igualdad de oportunidades" (Puyol, 2001: 117).

Estas tensiones se reflejan en los discursos sobre la igualdad de oportunidades:

Yo creo que en un país como EEUU sí existe la igualdad de oportunidades, un gallo que nace en un lugar de mucha humildad, de mucha carencia económica o de mucha dificultad, el gallo si hace las cosas correctas, si se le ponen los incentivos correctos, si tiene el apoyo correcto, es un niño o niña que va a poder aspirar al máximo. A eso tiene que aspirar Chile. A que cualquier ser humano que nazca en este país pueda tener las máximas aspira- 
ciones, así quiera ser un profesional, o un artista, o un empresario. Para mí, ese es el máximo. No es que no exista desigualdad, para mí el máximo es que los seres humanos puedan desarrollar sus potencialidades como quieran y sin que estén atrapados en el lugar donde nacieron, en la falta de educación, o en el apellido, esas son las desigualdades que molestan (Entrevista actor ámbito político, tendencia de derecha).

En Chile es muy radical pensar en igualdad de oportunidades incluso, porque tendrías que terminar con la herencia básicamente para tener igualdad de oportunidades. Y tenemos tan enquistado el rol y la importancia de la riqueza o de la acumulación, incluso de los sectores más precarios, que es muy difícil pensar en que culturalmente podemos avanzar hacia la igualdad de oportunidades. Es decir, terminar con la herencia... Es decir, estamos tratando un poco en estos procesos de reforma de caminar más o menos en esa línea, en ningún caso a poder hablar de igualdad de posiciones que es algo que yo creo que tenemos que avanzar hacia allá (Entrevista actor ámbito político, tendencia de izquierda).

\section{c) La sobrevaloración del mérito en un régimen neoliberal consolidado}

El neoliberalismo, que primero fue un laboratorio y luego un modelo instaurado en Chile, llevó a la reconstrucción de las fronteras entre el Estado y el mercado, y con ello a una transformación de las relaciones entre los grupos sociales (Araujo, 2013). El mercado se impuso como un ente regulador tanto del vínculo social, como del acceso a bienes y servicios básicos, incluyendo la educación y la salud.

En ese marco, la ya referida igualdad de oportunidades surge como fundamento de gran parte de la política social, en lo concreto, y como un principio normativo de justicia, en lo simbólico. Así, el mérito se asume con fuerza como uno de los principales "activos" de las personas para mejorar su calidad de vida. Proliferan de esta manera programas sociales centrados en las transferencias condicionadas y en el autoemprendimiento, asumiendo que a través de 
la ampliación de oportunidades operaría el esfuerzo y el mérito de las personas.

Los datos de la Encuesta LAPOP muestran que aún en el imaginario social se encuentra arraigada la visión de la "flojera" hacia quienes no pueden salir adelante por sus propios medios. Tal como lo señala la siguiente tabla, un $49,3 \%$ de los chilenos opina que quienes reciben ayuda de los programas sociales del gobierno son flojos:

Tabla N5. "Algunas personas dicen que la gente que recibe ayuda de los Programas sociales del gobierno es floja".

\begin{tabular}{|l|c|}
\hline Grado de acuerdo & $\%$ \\
\hline Desacuerdo & 50,7 \\
\hline Acuerdo & 49,3 \\
\hline
\end{tabular}

Fuente: Elaboración propia en base a Encuesta LAPOP 2012

Ahora bien, en un contexto altamente desigual como el chileno, donde la dispar distribución del ingreso va acompañada de otras formas de desigualdad, el mérito y la promoción del esfuerzo individual parece no estar funcionando.

Así lo explica uno de los entrevistados:

Sobre todo porque el enfoque de las meritocracias es un enfoque que no toma en consideración el aprecio o el valor que la sociedad le da al trabajo y cuán desigual distribuye la retribución, o el pago por así decirlo. Ya que mérito uno lo asocia a esfuerzo, ¿no? Pero en un modelo entre comillas perfectamente meritocrático, no tiene nada que ver con el esfuerzo. Tiene que ver con lo valiosa que sea la mercancía que tú produces a través de la fuerza del trabajo para la sociedad. O sea escribir una línea de códigos que te puede tomar cinco minutos puede ser más valioso que el trabajo que un obrero haga en un año. Entonces no tiene que ver con el esfuerzo, tiene que ver con el valor que éste genera. Por lo tanto la meritocracia es una teoría de justicia que excluye a todos quienes no han sido beneficiados por esa, entre comillas, productividad valorada por la sociedad. Podríamos decir que las perso- 
nas que tienen algún tipo de discapacidad, quien no tiene quizás las mismas habilidades cognitivas, está condenado a que por más esfuerzo que haga va a recibir una mala paga (Entrevista actor sector político, tendencia de izquierda).

Siguiendo sus alcances paradójicos, el imaginario social considera al esfuerzo y al mérito como promotores de igualdad, aun cuando se le asigna al Estado un rol central para reducir las brechas en el país.

Tabla No6. "El Estado debe implementar políticas firmes para reducir la desigualdad de ingresos entre ricos y pobres".

\begin{tabular}{|l|c|}
\hline Grado de acuerdo & $\%$ \\
\hline Desacuerdo & 12,4 \\
\hline Acuerdo & 87,6 \\
\hline
\end{tabular}

Fuente: Elaboración propia en base a Encuesta LAPOP 2012

Un mayoritario 87,6\% apela al Estado como responsable de la reducción de la desigualdad, lo que leído desde la igualdad de oportunidades promovida e incorporada en el imaginario social, lleva a suponer que la acción del Estado es pretendida respecto al "nivelado de cancha" que supone esta forma de comprender la justicia social, para que el mérito y el esfuerzo de las personas opere en condiciones iguales para todos.

Lo anterior es posible suponerlo porque, tal como lo muestra la tabla $\mathrm{N}^{\circ}$, no existe un ánimo de redistribución en el país. Es decir, se apela al Estado no en su rol redistributivo sino en tanto garante de las oportunidades para las personas. Un 60,4\% de las personas no está dispuesto a pagar más impuestos si estos se usaran para darle a quienes tienen menos:

Tabla N7. "Estaría dispuesto/a a pagar más impuestos si éstos se usaran para darle más a quien tiene menos".

\begin{tabular}{|l|c|}
\hline Grado de acuerdo & $\%$ \\
\hline Desacuerdo & 60,4 \\
\hline Acuerdo & 39,6 \\
\hline
\end{tabular}


Lo anterior es coherente con lo planteado por Alesina y La Ferrara (en Da Fonseca y Alenar, 2013): en aquellas sociedades donde se considera que el esfuerzo es la principal causa de las brechas de ingreso, hay una menor demanda redistributiva, lo que implica una baja tributación, alta inversión y variados incentivos al esfuerzo. Por el contrario, donde se considera que parte importante del ingreso está determinado por factores ajenos al control de las personas, la demanda por redistribución es mayor, existiendo una alta tributación, escasa inversión y desincentivos al esfuerzo.

El imaginario social en Chile sin duda se inclina por la primera alternativa, sin embargo -nuevamente- con algunas contradicciones:

Yo creo que hay una idea del rico bueno y del profesional esforzado. Está el imaginario del profesional que viene, se esfuerza y merece esa posición. El abogado, el médico, el ingeniero, todo en hombre además, porque ahí se mezcla con género. Ahora, es curioso todo este discurso, porque si uno ve, también se acompañan las mismas imágenes de los contrarios negativos. Por ejemplo, al profesional exitoso, se le acompaña aquel que llega a una posición de éxito en base a contactos y pitutos. Entonces cuando se dice que hay legitimidad de la desigualad, hay dos tesis circulando en Chile, así a nivel de academia (Entrevista actor sector académico).

El peso del mérito dentro del imaginario se devela en engañosas visiones sobre la sociedad: en palabras de Araujo (2013), se instala una imagen positiva respecto a las posibilidades de movilidad social, una alta valoración a la ambición personal, la importancia del esfuerzo y de las ganas de tener éxito. Además, mediante la promesa del mérito, señala la autora, se extiende la competencia, el consumo y el crédito como una 'promesa igualitaria sui generis'.

En palabras de una de las entrevistadas, respecto a la igualdad de oportunidades y el mérito como motor de igualdad:

Bueno, la igualdad de oportunidades tiene el problema básico de que reconoce una igualdad formal, pero no reconoce el con- 
texto, las condiciones para conseguir los bienes que considera valiosos para vivir una vida valorable. Entonces si no se considera el contexto, de qué meritocracia estamos hablando, o sea, es más bien un discurso, una ideología, más que una forma de entender la desigualdad (Entrevista actor 2 sector académico).

Para Zilvetti (2016), el mérito es, en el discurso social, una medida de justicia y también un atributo moral. Es decir, utilizado tanto para juzgar la justicia en la sociedad como para valorar los logros individuales. Ahí sucede que la noción de responsabilidad individual es el principal determinante que tiende a prevalecer en la opinión de las personas, mientras que el impacto de factores estructurales es menos referido por los individuos (Bucca, 2016).

La confianza depositada en el mérito y en la responsabilidad individual en la promoción de la justicia social, no ha traído consigo resultados en términos de reducción de la desigualdad. Ello lleva a concluir que el mérito está sobrevalorado en Chile, reforzado por el rol que ocupa el mercado en el régimen neoliberal chileno que fragmenta y tensiona la acción del Estado en materia redistributiva y de promoción de igualdad socioeconómica.

Así, de acuerdo a Zilvetti (2016), el mérito se constituye como un criterio hegemónico para legitimar la distribución desigual de recompensas, percibir injusticia cuando las recompensas no obedecen a criterios meritocráticos, reconocer a personas que obtienen resultados valorados producto del mérito individual. Se esconden, de esta forma, aquellos atributos estructurales que reproducen la desigualdad, ampliando la legitimidad que la percepción colectiva le da a la desigualdad de los ingresos y atribuyendo la posición que cada individuo asume en la estructura social únicamente a las características de cada persona.

\section{Reflexiones finales}

La experiencia investigativa en torno a los imaginarios sociales, en este caso, sobre la igualdad y la desigualdad en Chile, dejan interesantes aprendizajes que en virtud de los objetivos propuestos 
para el artículo, sirven de reflexiones pertinentes a la disciplina del Trabajo Social y su constante búsqueda de comprensión compleja y transformación social.

Como se señalara en la presentación, al Trabajo Social lo sacude una profunda vocación por el cambio. Ahora bien, las corrientes disciplinares contemporáneas, por un lado, y la complejidad y persistencia de los problemas sociales, por otro, no hacen sino más que insistir en que la pura acción profesional no alcanza para satisfacer su propio deseo transformativo.

La acción profesional finalmente es parte de un dispositivo mayor y más complejo, la intervención social, que incluye procesos no sólo metodológicos sino también teóricos y conceptuales. Estos permiten desplazar los límites de la comprensión e interpretación hacia las fronteras simbólicas y representativas acerca de lo social. Ello es de relevancia para la profesión, pues mientras no cuestionemos aquello que llamamos 'lo social', lo dejaremos como algo naturalizado, cuando en verdad se trata de construcciones históricas y culturales ligadas a la manera en que lo interpretamos.

De esta forma, el concepto de imaginarios sociales nos remite justamente a visualizar aquello que damos por 'real' como esquemas de representación que estructuran la experiencia social y le dan sentido a una realidad construida y compartida históricamente.

Así, se pueden proponer al menos tres reflexiones acerca de la utilidad de los imaginarios sociales para la disciplina.

La primera dice relación con la posibilidad de desnaturalizar problemas sociales que, como la desigualdad, se mantienen fuertemente arraigados en la cotidianidad colectiva. Este arraigo es riesgoso para los horizontes de la transformación social, pues aquello que se considera natural, no es transformable. Inmiscuirse dentro de los imaginarios sociales resulta ser un gran aliado del cambio que promueve el Trabajo Social toda vez que nos llevan, inevitablemente, a aquellos espacios simbólicos que le dan significado y sentido a los fenómenos y problemas sociales, permitiendo enton- 
ces comprenderlos como construcciones y no como dados naturalmente. En ese caso, la transformación es posible.

En segundo lugar, los imaginarios sociales abren las fronteras de la comprensión social. Ello porque nos permiten diferenciar entre las representaciones colectivas forjadas en una sociedad, de aquellos marcos de interpretación que le asignan características particulares a los problemas sociales. En el caso de la igualdad y la desigualdad, el destape del mérito como una dimensión sobrevalorada de justicia permite hacer entrar al terreno de juego, los factores y dimensiones estructurales que rodean las inequidades en el país. Así, es posible entonces que el Trabajo Social amplíe la mirada, busque nuevas formas de interpretación acerca del mérito, tensione los principios de justicia que existen en las personas y demande nuevas líneas de acción públicas y privadas a favor de la igualdad. Al igual como permanentemente apelamos al esfuerzo y capacidades de las personas, ¿será también nuestra responsabilidad apelar a reformas redistributivas? Por supuesto que sí. Y aunque nuestros marcos de acción profesional difícilmente se encuentran en los espacios de decisión política, es claro que en lo cotidiano y en ese privilegiado 'cara a cara' podemos empujar cambios interpretativos respecto a la estructura que reproduce problemas como la desigualdad. Y lo mismo respecto a la pobreza, a la violencia, a la discriminación y a la exclusión, por nombrar algunos otros.

Por último, la tercera reflexión, propone que los imaginarios sociales son un recurso valioso para promover cambios de actitudes, comportamientos y especialmente de adhesión a determinados valores que aceptamos -o no- como sociedad. Pensemos que la desigualdad sigue siendo considerada como difícil de cambiar pero ya existen discursos que claramente la critican. Si la criticamos, o más bien, si el imaginario predominante tiende a no tolerarla, el intento de transformación ensancha sus posibilidades. ¿Hubiera sido posible en Chile una ley de violencia intrafamiliar si ésta siguiera siendo considerada un problema privado? O, ¿dos personas del mismo sexo pudieran legalizar su vínculo si la discusión y apertura valórica no hubiera manifestado un giro en parte im- 
portante de la población? Estos dos ejemplos, en algo evidencian el peso de los imaginarios sociales sobre la vida de las personas.

\section{Bibliografía}

Araujo, K. (2013a). Interactive Inequalities and Equality in the Social Bond: A Sociological Study of Equality. Working Paper Series 54, desiguALdades.net International Research Network on Interdependent Inequalities in Latin America.

Araujo, K. (2013B). La igualdad en el lazo social: procesos sociohistóricos y nuevas percepciones de la desigualdad en la sociedad chilena. En Revista de Ciencias Sociales, Río de Janiero, vol. 56, n ${ }^{\circ}$, pp. 109 a 132.

Baczko, B. (1991). Los imaginarios sociales. Memorias y esperanzas colectivas. Buenos Aires: Ediciones Nueva Visión.

Baeza, M. (2000). Los caminos invisibles de la realidad social. Ensayos de sociología profunda sobre imaginarios sociales. Santiago: Ediciones Sociedad Hoy.

Banco Mundial (2012). World Development Indicators. Washington, EEUU.

Banco Mundial (2016). World Development Indicators. Washington, EEUU.

Bucca, M. (2016). Merit and blame in unequal societies: explaining Latin American's beliefs about wealth and poverty. En Research in Social Stratification and Mobility, vol. 44, pp. 98-112.

Castillo, J. (2009). ¿Cuál es la Brecha Salarial Justa? Opinión Pública y Legitimación de la desigualdad Económica en Chile. Estudios Públicos $\mathrm{N}^{\circ} 113$, pp. 237-266.

Castillo, J. (2012a). Is inequality becoming just? Changes in public opinion about economic distribution in Chile. En Bulletin of Latin America Research, Vol. 31, N¹, pp. 1-18.

Castillo, J. (2012b). La legitimidad de las desigualdades salariales. Una aproximación multidimensional. En Revista Internacional de Sociología (online), manuscrito aceptado. Doi: 10.3989/ ris.2010.11.22.

Castoriadis, C. (2006). Una sociedad a la deriva. Entrevistas y debates (1974-1997). Katz Editores.

CEPAL (2012). Panorama Social para América Latina 2012. Naciones Unidas, Chile.

Da Fonseca, C. y Alencar, E. (2013). Movilidad social y demanda de redistribución del ingreso en América Latina. Revista de la Cepal No110, pp. 69-84. 
Dubet, F. (2011). Repensar la justicia social. Buenos Aires: Siglo XXI Editores.

Flotts, M. (2016). El complejo tejido conceptual de la (des)igualdad: implicancias para una sociedad más justa. En Contreras, A. (compiladora, Las desigualdades sociales como campo de investigación en Trabajo Social, pp. 55-68. Editorial Espacio y Universidad Católica Silva Henríquez.

Garretón, M.A. y Cumsille, G. (2000). Las percepciones de la desigualdad en Chile. SUR Ediciones.

Huber, E., Pribble, J. et al. (2006). Politics and Inequality in Latin Ameri$\mathrm{ca}$ and the Caribbean. American Sociological Review $\mathrm{N}^{\circ} 71$, pp.943-963.

OECD (2015). Todos Juntos ¿Por qué reducir la desigualdad nos beneficia? OECD.

Ottone, E. y Vergara, C. (2007). La desigualdad social en América Latina y el caso chileno. Estudios Públicos, 108. Centro de Estudios Públicos.

Pintos, J.L. (1995). Los imaginarios sociales. La nueva construcción de la realidad social. Madrid: Editorial Sal Terrae.

Puga, I. (2011). Lo justo y lo posible: desigualdad, legitimidad e ideología en Chile. En Desigualdad, legitimación y conflicto. Dimensiones politicas y culturales de la desigualdad en América Latina. Chile: Ediciones Universidad Alberto Hurtado.

Puyol, Á. (2001). El Discurso de la igualdad. Crítica, Barcelona.

Sen, A. (1992). Nuevo examen de la desigualdad. Madrid: Alianza Editorial.

Taylor, C. (2006). Imaginarios sociales modernos. Barcelona: Paidós.

Zilveti, M. (2016). Mérito, justicia y desigualdad. Elementos discursivos para el estudio de la desigualdad en Chile a partir de ocho grupos de discusión. Serie de Documentos de Trabajo PNUD- Desigualdad N²016/3. 